\title{
Cognitive decline in normal aging and its prevention: a review on non-pharmacological lifestyle strategies
}

\author{
This article was published in the following Dove Press journal: \\ Clinical Interventions in Aging \\ 25 May 2017 \\ Number of times this article has been viewed
}

\author{
Blanka Klimova ${ }^{1,2}$ \\ Martin Valis ${ }^{2}$ \\ Kamil Kuca ${ }^{3,4}$ \\ 'Department of Applied Linguistics, \\ Faculty of Informatics and \\ Management, University of Hradec \\ Kralove, ${ }^{2}$ Department of Neurology, \\ ${ }^{3}$ Biomedical Research Centre, \\ University Hospital Hradec Kralove, \\ ${ }^{4}$ Department of Chemistry, Faculty of \\ Science, University of Hradec Kralove, \\ Hradec Kralove, Czech Republic
}

\begin{abstract}
The purpose of this study is to examine the effects of the selected non-pharmacological lifestyle activities on the delay of cognitive decline in normal aging. This was done by conducting a literature review in the four acknowledged databases Web of Science, Scopus, MEDLINE, and Springer, and consequently by evaluating the findings of the relevant studies. The findings show that physical activities, such as walking and aerobic exercises, music therapy, adherence to Mediterranean diet, or solving crosswords, seem to be very promising lifestyle intervention tools. The results indicate that non-pharmacological lifestyle intervention activities should be intense and possibly done simultaneously in order to be effective in the prevention of cognitive decline. In addition, more longitudinal randomized controlled trials are needed in order to discover the most effective types and the duration of these intervention activities in the prevention of cognitive decline, typical of aging population groups.
\end{abstract}

Keywords: cognitive impairment, healthy older individuals, intervention, benefits

\section{Background}

Cognitive skills play a crucial role in the daily functioning of older people. Unfortunately, some of these cognitive skills (eg, memory, problem-solving activities, or speed processing) decline in the process of aging. ${ }^{1-4}$ There are several risk factors which appear to have an impact on cognitive decline. ${ }^{5}$ These risk factors can be divided into modifiable and non-modifiable risk factors. The non-modifiable risk factors include age, race and ethnicity, gender, and genetics. ${ }^{6}$ In fact, it has been proved that $60 \%$ of general cognitive ability is of genetic origin. ${ }^{7}$ The modifiable risk factors mainly involve diabetes, head injuries, lifestyle, and education. ${ }^{8}$

Furthermore, Klimova and $\mathrm{Kuca}^{9}$ divide the non-pharmacological lifestyle intervention activities into three most influential groups which have a positive impact on cognitive decline: physical activities, healthy diet, and cognitive training. These activities have a positive effect on the maintenance of synaptic function whose loss is usually connected with toxic forms of amyloid- $\beta$ protein, which can result in the onset of aging diseases such as dementia. However, thanks to the non-pharmacological activities and their intensity, this synapse and synaptic protein loss may be prevented. In addition, physical activities can contribute to the increase of vascularization, energy metabolism, and resistance against oxidative stress, which has a positive effect on cognitive functions. ${ }^{10}$ Recent research ${ }^{11,12}$ has also revealed beneficial effects of music therapies in the prevention of cognitive decline. Since there are findings ${ }^{13-16}$ that certain non-pharmacological lifestyle activities such as physical activities or adherence

\author{
Correspondence: Kamil Kuca \\ University Hospital Hradec Kralove, \\ Sokolska 58I, Hradec Kralove 500 05, \\ Czech Republic \\ Tel +420 603289166 \\ Fax +420 495835200 \\ Email kamil.kuca@fnhk.cz
}


to Mediterranean diet (MedDiet) may contribute to the prevention of cognitive aging, the purpose of this study is to examine the effects of the selected non-pharmacological lifestyle activities on the delay of cognitive decline in normal aging. This is done on the basis of the findings from the selected studies. Since pharmacological intervention is relatively costly, might have serious side effects, and impose a severe social burden, the main purpose of this review is to analyze and compare the effects of non-pharmacological activities - physical activities/exercises, adherence to MedDiet, music therapy, and cognitive training such as solving crosswords - on the prevention of cognitive decline in normal aging. ${ }^{17}$

\section{Methods}

The methodology used in this review is based on the study of Moher et al. ${ }^{18}$ The relevant studies were searched using key words in four acknowledged databases: Web of Science, Springer, Scopus, and MEDLINE. This review screened for studies conducted in the period from 2000 to June 2016, using the following key words: cognitive skills in normal aging AND intervention strategies; healthy older people AND cognitive decline AND physical activities; healthy older people AND cognitive decline AND physical exercises; healthy older people AND cognitive decline AND Mediterranean diet; and healthy older people AND cognitive decline AND music.

A study was included if it matched the corresponding period, from 2000 up to June 2016. The selection period started with the year of 2000 because this is the year when the studies on the research topic conducted among older people started to appear. Furthermore, the study was included if it involved healthy older people without any cognitive impairment or dementia, aged 60+ years, and focused on the topic of non-pharmacological lifestyle intervention strategies, that is, physical activities/exercises, adherence to MedDiet, music therapy, or mental activity such as solving a crossword. All studies had to be written in English to be included in this review.

This review included randomized controlled trials (RCTs), observational studies, descriptive studies, retrospective studies, theoretical articles, reviews, books, book chapters, web pages, study protocols, seminar papers, and abstracts on the research topic. The majority of the included studies were detected in the Springer database (14,641 studies), followed by Web of Science (110 studies), Scopus (61 studies), and MEDLINE (38 studies). Altogether 14,850 studies were found via the database search, and 176 from other available

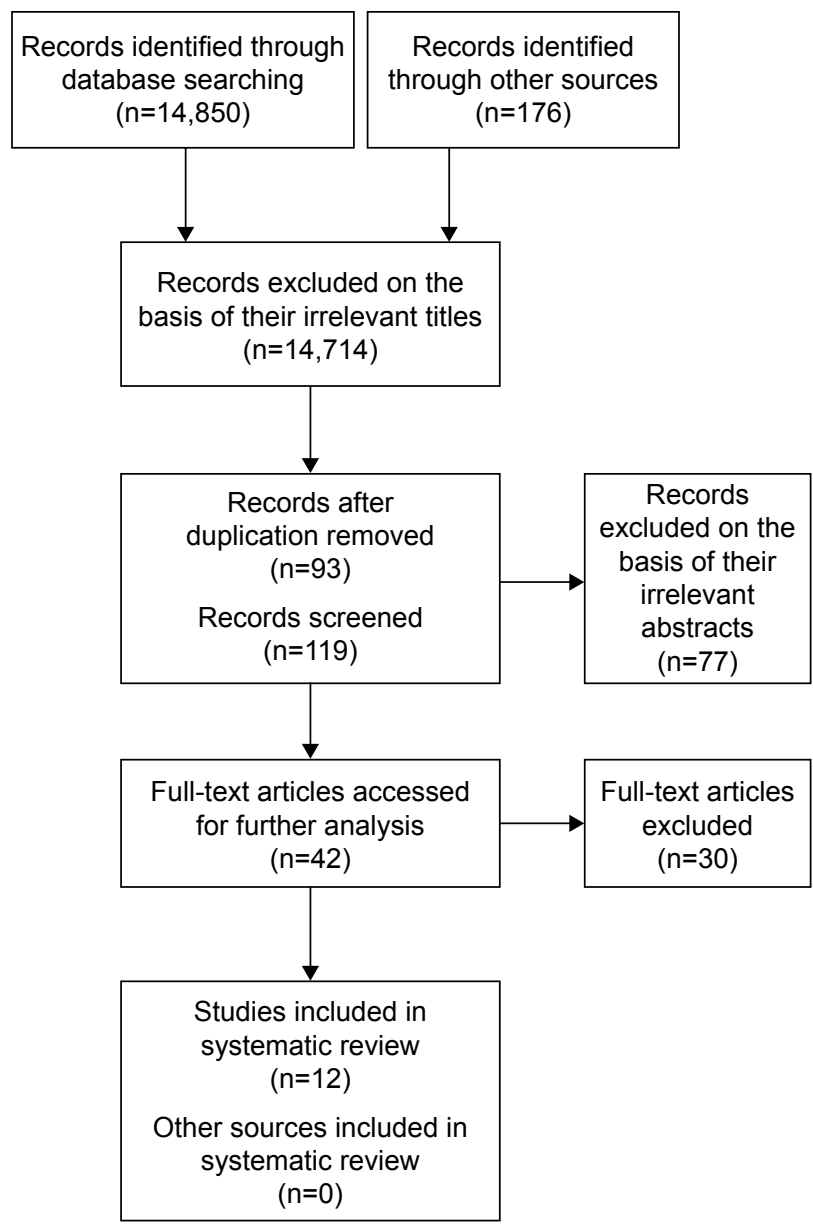

Figure I Flowchart of the selection procedure.

sources (ie, web pages, conference proceedings, and books outside the scope of the databases described above). Then, the titles of all the included studies were checked in order to confirm whether they focus on the research topic, and irrelevant studies were excluded. In addition, duplicate studies were also excluded. After this step, 119 studies remained for further analysis. Afterwards, the authors checked the content of the abstracts to verify whether the study examined the relevant research topic. Finally, 42 studies/articles were selected for the full-text analysis, out of which the findings of 30 studies are compared in the present review and the remaining 12 studies were used for the detailed analysis of the research topic (Figure 1). The rigid process of selection of these studies is described in Figure 1.

\section{Findings}

Altogether 12 studies focusing on the research topic were identified. Out of these studies, six exclusively focused on physical activities, two on MedDiet, two on a music therapy, one on an educational program, and one on doing crosswords. 
The intervention period in the studies ranged from 2 weeks to 6.5 years. The subject samples also varied; the smallest sample of subjects consisted of 21 older individuals, whereas the largest one involved 716 older adults. The efficacy of the intervention therapies focused on the prevention of cognitive decline in the studies was measured with the available validated cognitive assessment tools such as cognitive tests and/or magnetic resonance imaging. Table $1^{19-28}$ provides an overview of the main findings of these studies. The results are summarized in alphabetical order of their first author name.

The findings of all studies in Table 1 exhibit positive results as far as cognitive functions (ie, executive functions, better memory, learning, attention, or verbal fluency) are concerned. Based on the evidence of the outcome measures, all studies indicate that cognitive functions can be maintained or even enhanced by intervention activities such as sport (eg, walking or aerobic exercises), music, healthy MedDiet, or doing crosswords. The findings also suggest that the immediate results may be detected after intervening for just 1 month. However, this is questionable because according to Kurz and van Baelen, ${ }^{29}$ the minimum period for medication assessment as suggested by regulatory authorities is 24 weeks.

\section{Discussion}

The findings from the selected studies in Table 1 are discussed in this section according to their representation of intervention activities. Thus, the majority of studies deal with physical activities. The results show that people who do more physical activities per day have a lower incidence of cognitive decline compared with those doing them occasionally. The same is true for their intensity. For example, Larson et $\mathrm{al}^{30}$ claim that intensive physical activities may delay the decline of cognitive functioning. They indicate that people who exercise three times a week or more fall ill with dementia less compared with those who conduct physical exercises less than three times a week. Thus, it seems that healthy older people who do physical activities regularly and intensively at least two to three times a week may enhance their cognitive functions. However, another study performed for a period of 15 years by Sorman et $\mathrm{a}^{31}$ among 1,475 healthy individuals aged 65 years and above shows that the positive outcomes of these physical activities may be valid just for a shorter time span, but there is a little support for the effect of the physical activities in the prevention of cognitive decline in a longer time span. This is also supported by a review, ${ }^{19}$ whose authors report that the benefits of physical activity are small and cumulative over many years and they may be beyond resolution by RCTs.

Studies ${ }^{11,12,32,33}$ also emphasize the role of music therapy, especially listening to Buddhist hymns, ${ }^{12}$ in the improvement of cognitive competences because music may recall past memories and activate patient's brain more as affects both the hemispheres of the brain. In fact, music comprehension is connected with one specific area of the brain that remains intact even after all other functions, such as verbal language, are impaired. ${ }^{34}$ For example, a study ${ }^{12}$ shows that the results obtained over a 4-month follow-up period revealed a significant difference between the experimental group and comparison group in cognitive scores. After 4 months, a significant decline in the Mini-Mental State Examination score compared with the initial score was observed in the comparison group, but not in the experimental group. Furthermore, Craig ${ }^{33}$ suggests that music therapies should be done in groups in order for them to be effective, that is, regularly twice a week, and patients should be exposed to such kind of music that is familiar to them and in which they are engaged.

Furthermore, some studies ${ }^{22,28}$ prove the benefits of MedDiet, especially if it is rich in olive oil and nuts. Recent studies $^{35-37}$ indicate that a proper dietary regime plays a crucial role in the maintenance of optimal synoptic function.

The findings of the analyzed studies also prove the efficacy of solving crosswords on cognitive decline ${ }^{24}$ because learning something new and training the brain may lower the risk of cognitive decline. ${ }^{10}$ However, they must be done several times a week. For example, Verghese et $\mathrm{al}^{38}$ in their study confirm that if a person solves crosswords four times a week, she/he can reduce the risk of dementia by $47 \%$ compared with the person who does it only once a week.

Recent studies have revealed that the most effective type of intervention activity seems to be the one which consists of several intervention activities. ${ }^{39,40}$ Nevertheless, these activities must be done on a regular basis, ideally several times a week, and people should start with them in their middle age. ${ }^{41}$

The limitations of this review are the lack of available RCTs on the research issue and the different methodologies of the included publications such as the use of passive control groups, or no intervention group at all, or small subject samples. These insufficiencies may result in the overestimated effects of the discussed findings and have a negative impact on the validity of the reviewed studies. ${ }^{42-44}$ The heterogeneity of the selected studies also prevented the authors from conducting the meta-analysis. 


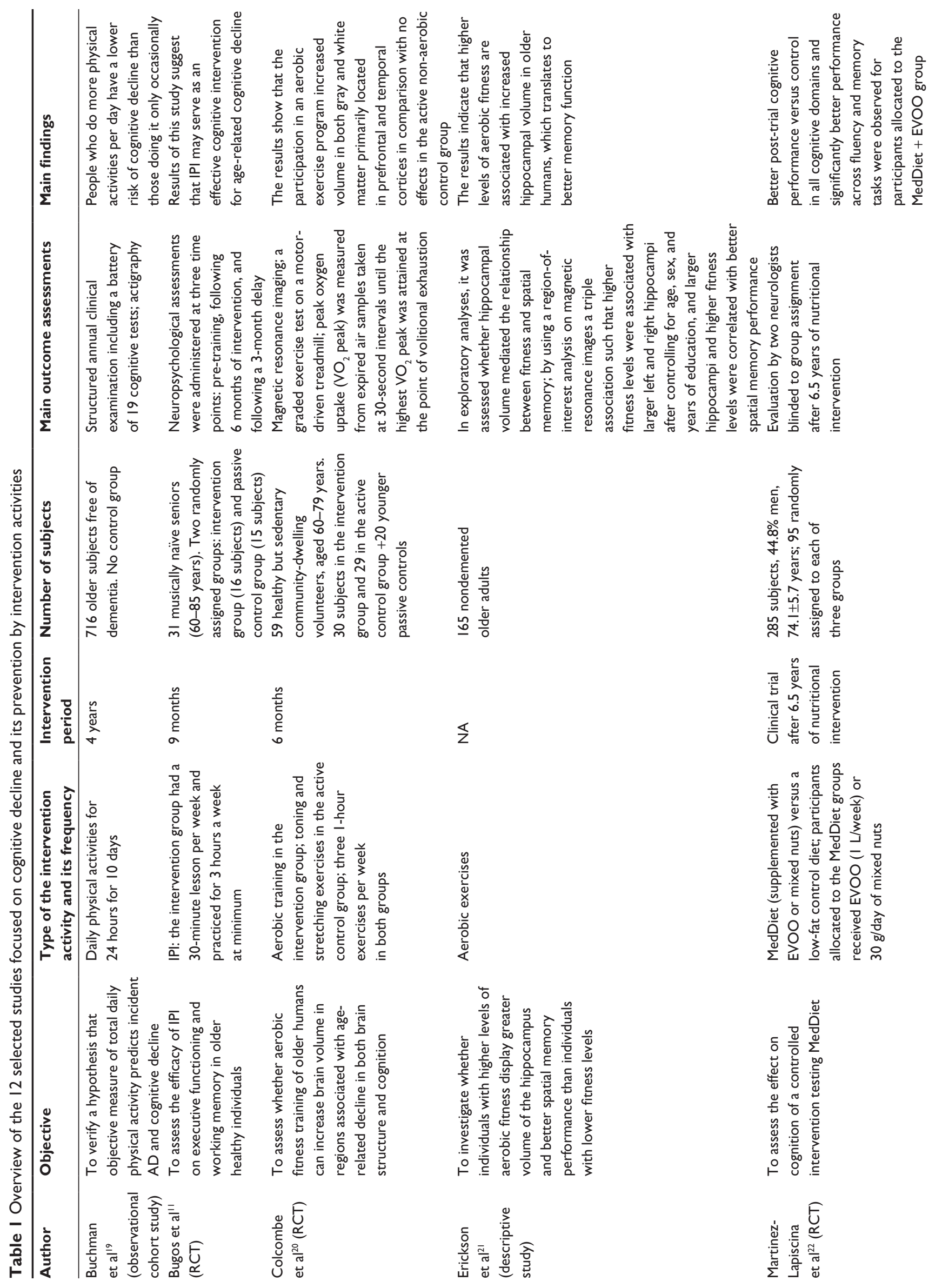



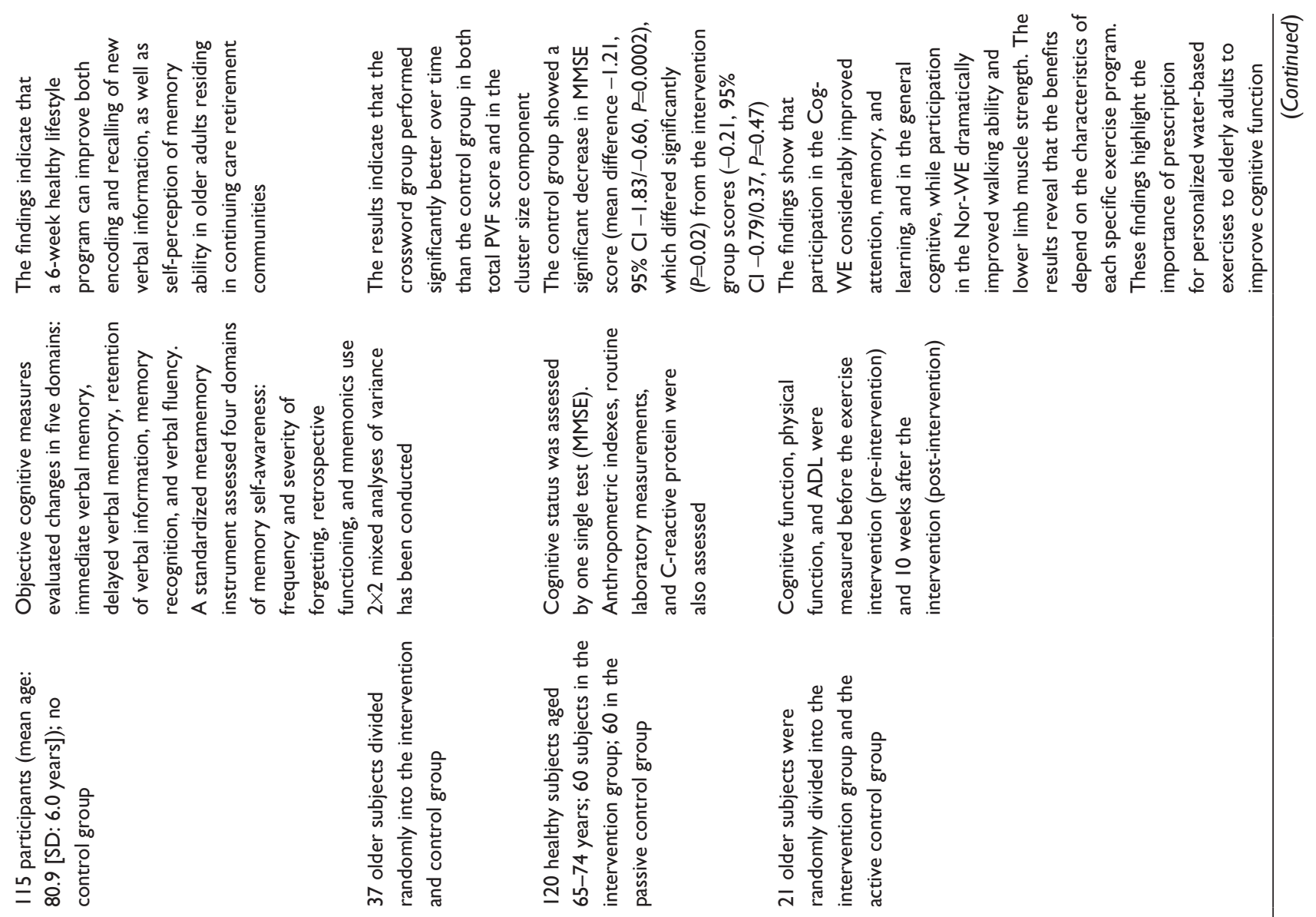

$\frac{\tilde{c}}{\tilde{0}}$
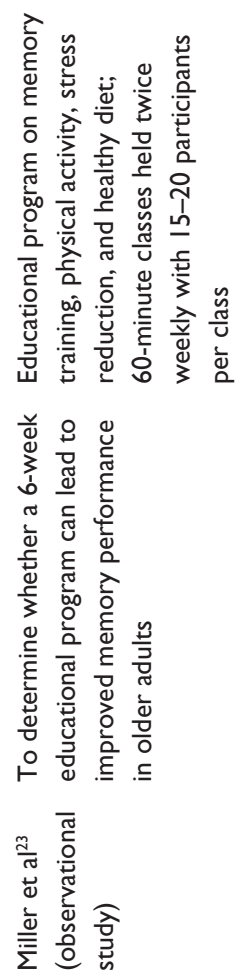
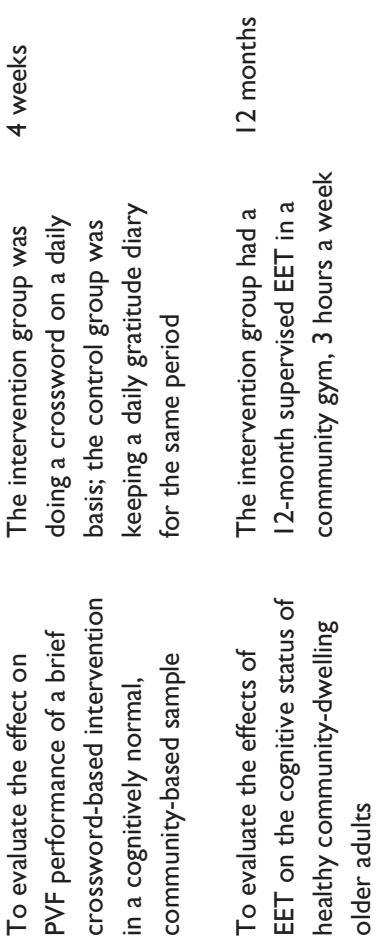

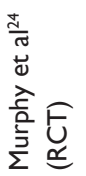
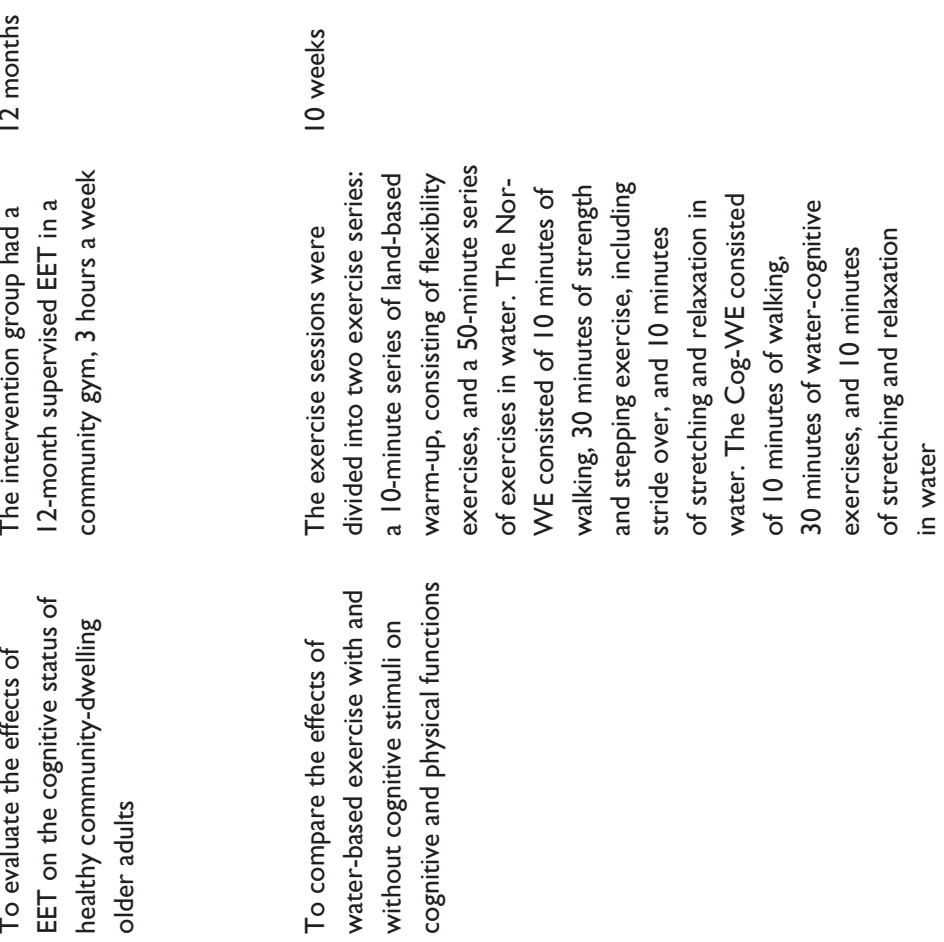

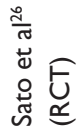




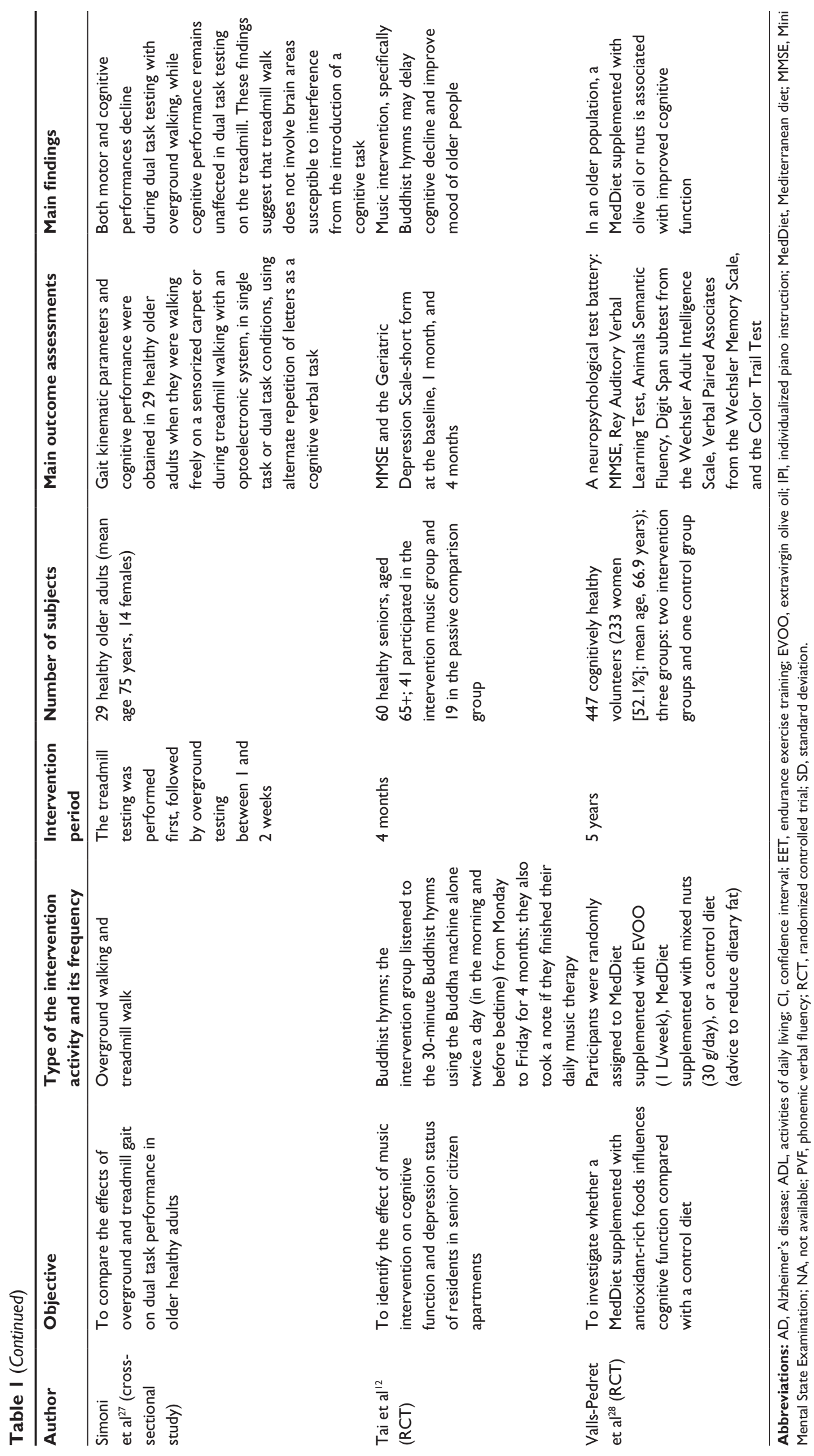




\section{Conclusion}

The results of this review indicate that all the selected nonpharmacological lifestyle intervention strategies explored appear to have positive effects on the cognitive functions in older people. These therapies are generally less costly and noninvasive in comparison with the pharmacological treatment, which is usually lengthy and brings about possible side effects. Older people also have a chance to meet with their peers while performing these preventive non-pharmacological therapies. Nevertheless, the findings of this study also suggest that future research should focus on conducting more longitudinal RCTs with larger samples of subjects in order to discover the most effective types and the duration of these intervention activities for the prevention of cognitive decline, typical of aging population groups.

\section{Acknowledgments}

This paper was supported by the project Excelence 2017 run at the Faculty of Informatics and Management of the University of Hradec Kralove and the long-term development plans of the University Hospital Hradec Kralove and University of Hradec Kralove.

\section{Disclosure}

The authors declare that they have no competing interests to declare in this work.

\section{References}

1. Harada CN, Natelson Love MC, Triebel K. Normal cognitive aging. Clin Geriatr Med. 2013;29(4):737-752.

2. Reichman WE, Fiocco AJ, Rose NS. Exercising the brain to avoid cognitive decline: examining the evidence. Aging Health. 2010;6(5): 565-584.

3. Craik F, Salthouse T. The Handbook of Aging and Cognition. 2nd ed. Mahwah, NJ: Lawrence Erlbaum; 2002.

4. Salthouse T. Consequences of age-related cognitive declines. Annu Rev Psychol. 2012;63:201-226.

5. Barnes DE, Yaffe K. The projected effect of risk factor reduction on Alzheimer's disease prevalence. Lancet Neurol. 2011;10(9):819-828.

6. Deary IJ, Corley J, Gow AJ, et al. Age-associated cognitive decline. Br Med Bull. 2009;92:132-152.

7. McClearn GE, Johansson B, Berg S, et al. Substantial genetic influence on cognitive abilities in twins 80 or more years old. Science. 1997;276: 1560-1563.

8. Norton S, Matthews FE, Barnes DE, Yaffe K, Brayne C. Potential for primary prevention of Alzheimer's disease: an analysis of populationbased data. Lancet Neurol. 2014;13(8):788-794.

9. Klimova B, Kuca K. Alzheimer's disease: potential preventive, noninvasive, intervention strategies in lowering the risk of cognitive decline - a review study. J Appl Biomed. 2015;13(4):257-261.

10. Clare R, King VG, Wirenfeldt M, Vinters HV. Synapse loss in dementias. J Neurosci Res. 2010;88(10):2083-2090.

11. Bugos JA, Perlstein WM, McCrae CS, Brophy TS, Bedenbaugh PH. Individualized piano instruction enhances executive functioning and working memory in older adults. Aging Ment Health. 2007;11(4):464- 471.

12. Tai S-Y, Wang L-C, Yang Y-H. Effect of music intervention on the cognitive and depression status of senior apartment residents in Taiwan. Neuropsychiatr Dis Treat. 2015;11:1449-1454.
13. Klimova B, Maresova P, Kuca K. Non-pharmacological approaches to the prevention and treatment of Alzheimer's disease with respect to the rising treatment costs. Curr Alzheimer Res. 2016;13(11):1249-1258.

14. Erickson KI, Kramer AF. Aerobic exercise effects on cognitive and neural plasticity in older adults. Br J Sports Med. 2009;43(1):22-24.

15. Bherer L, Erickson KI, Liu-Ambrose T. A review of the effects of physical activity and exercise on cognitive and brain functions in older adults. J Aging Res. 2013;2013:ID657508.

16. Tagney CC. DASH and Mediterranean-type dietary patterns to maintain cognitive health. Curr Nutr Rep. 2014;3(1):51-61.

17. Maresova P, Klimova B, Novotny M, Kuca K. Alzheimer's disease and Parkinson's diseases: expected economic impact on Europe - a call for a uniform European strategy. J Alzheimers Dis. 2016;54(3):1123-1133.

18. Moher D, Liberati A, Tetzlaff J, Altman DG. The PRISMA Group. Preferred reporting items for systematic review and meta-analysis: the PRISMA statement. PLoS Med. 2009;6(7):e1000097.

19. Buchman AS, Boyle PA, Yu L, Shah RC, Wilson RS, Bennett DA. Total daily physical activity and the risk of AD and cognitive decline in older adults. Neurology. 2012;78(17):1323-1329.

20. Colcombe SJ, Erickson KI, Scalf PE, et al. Aerobic exercise training increases brain volume in aging humans. J Gerontol A Biol Sci Med Sci. 2006;61(11):1166-1170.

21. Erickson KI, Prakash RS, Voss MW, et al. Aerobic fitness is associated with hippocampal volume in elderly humans. Hippocampus. 2009; 19(10):1030-1039.

22. Martinez-Lapiscina EH, Clavero P, Toledo E, et al. Virgin olive oil supplementation and long-term cognition: the PREDIMED-NAVARRA randomized, trial. J Nutr Health Aging. 2013;17(6):544-552.

23. Miller KJ, Siddarth P, Gaines JM, et al. The memory fitness program: cognitive effects of a healthy aging intervention. Am J Geriatr Psychiatry. 2012;20(6):514-523.

24. Murphy M, O'Sullivan K, Kelleher KG. Daily crosswords improve verbal fluency: a brief intervention study. Int J Geriatr Psychiatry. 2014; 29(9):915-919.

25. Muscari A, Giannoni C, Pierpaoli L, et al. Chronic endurance exercise training prevents aging-related cognitive decline in healthy older adults: a randomized controlled trial. Int J Geriatr Psychiatry. 2010;25(10): 1055-1064.

26. Sato D, Seko C, Hashitomi T, Sengoku Y, Nomura T. Differential effects of water-based exercise on the cognitive function in independent elderly adults. Aging Clin Exp Res. 2015;27(2):149-159.

27. Simoni D, Rubbieri G, Baccini M, et al. Different motor tasks impact differently on cognitive performance of older persons during dual task tests. Clin Biomech (Bristol Avon). 2013;28(6):692-696.

28. Valls-Pedret C, Sala-Vila A, Serra-Mir M, et al. Mediterranean diet and age-related cognitive decline: a randomized clinical trial. JAMA Intern Med. 2015;175(7):1094-1103.

29. Kurz A, van Baelen B. Ginkgo biloba compared with cholinesterase inhibitors in the treatment of dementia: a review based on meta-analyses by the Cochrane collaboration. Dement Geriatr Cogn Disord. 2004;18(2): $217-226$.

30. Larson EB, Wang L, Bowen JD, et al. Exercise is associated with reduced risk for incident dementia among persons 65 years of age and older. Ann Intern Med. 2006;144(2):73-81.

31. Sorman DE, Sundstrom A, Ronnlund M, Adolfsson R, Nilsson LG. Leisure activity in old age and risk of dementia: a 15-year prospective study. J Gerontology B Psychol Sci Soc Sci. 2014;69(4):493-501.

32. Balbag MA, Pedersen NL, Gatz M. Playing a musical instrument as a protective factor against dementia and cognitive impairment: a population-based study. Int J Alzheimers Dis. 2014;2014:836748.

33. Craig J. Music therapy to reduce agitation in dementia. Nurs Times. 2014; 10(32-33):12-15.

34. Cooke M, Moyle W, Shum D, Harrison S, Murfield J. A randomized controlled trial exploring the effect of music on quality of life and depression in older people with dementia. J Health Psychol. 2010;15(5): 765-776.

35. Arab L, Sabbagh MN. Are certain life style habits associated with lower Alzheimer disease risk? J Alzheimers Dis. 2010;20(3):785-794. 
36. Swaminathan A, Jicha GA. Nutrition and prevention of Alzheimer's dementia. Front Aging Neurosci. 2014;6:282.

37. Mosconi L, Murray J, Tsui WH, et al. Mediterranean diet and magnetic resonance imaging-assessed brain atrophy in cognitively normal individuals at risk for Alzheimer's disease. J Prev Alzheimers Dis. 2014; 1(1):23-32.

38. Verghese JM, Lipton RB, Katz MJ, et al. Leisure activities and the risk of dementia in the elderly. N Engl J Med. 2003;348:2508-2516.

39. Fissler P, Kolassa I-T, Schrader C. Educational games for brain health: revealing their unexplored potential through a neurocognitive approach. Front Psychol. 2015;6:1056.

40. Paillard T, Rolland Y, de Sonto Barreto P. Protective effects of physical exercise in Alzheimer's disease and Parkinson's disease: a narrative review. J Clin Neurol. 2015;11(3):212-219.
41. Melby-Lervag M, Hulme C. There is no convincing evidence that working memory training is effective: a reply to Au et al. (2014) and Karbach and Verhaeghen (2014). Psychon Bull Rev. 2016;23(1): 324-330.

42. Melby-Lervag M, Hulme $\mathrm{C}$. Is working memory training effective? A meta-analytic review. Dev Psychol. 2013;49(2):270-291.

43. Klimova B. Use of the Internet as a prevention tool against cognitive decline in normal aging. Clin Interv Aging. 2016;11:1231-1237.

44. Maresova P, Mohelska H, Dolejs J, Kuca K. Socio-economic aspects of Alzheimer's disease. Curr Alzheimer Res. 2015;12(9):903-911.
Clinical Interventions in Aging

\section{Publish your work in this journal}

Clinical Interventions in Aging is an international, peer-reviewed journal focusing on evidence-based reports on the value or lack thereof of treatments intended to prevent or delay the onset of maladaptive correlates of aging in human beings. This journal is indexed on PubMed Central, MedLine,

\section{Dovepress}

CAS, Scopus and the Elsevier Bibliographic databases. The manuscript management system is completely online and includes a very quick and fair peer-review system, which is all easy to use. Visit http://www.dovepress. com/testimonials.php to read real quotes from published authors. 